\title{
AS TEORIAS DA AÇÃO E DOS SISTEMAS PODEM SER ASSOCIADAS? PRESSUPOSTOS DA TEORIA DOS SISTEMAS DE PARSONS E LUHMANN E DA TEORIA DA AÇÃO DE WEBER ${ }^{1}$ \\ CAN THEORIES OF ACTION AND SYSTEMS BE ASSOCIATED? ASSUMPTIONS ABOUT THE SYSTEMS THEORY OF PARSONS AND LUHMANN AND THE ACTION THEORY OF WEBER
}

\author{
Thomas SCHWINN \\ Universität Heidelberg, Heidelberg, Alemanha \\ thomas.schwinn@mwi.uni-heidelberg.de
}

Mais informações da obra no final do artigo

\begin{abstract}
RESUMO
$\mathrm{Na}$ teoria sociológica não há consenso sobre como associar as teorias da ação (como a abordagem clássica de Max Weber) e dos sistemas (como as abordagens de Talcott Parsons e de Niklas Luhmann). Ao reconhecer que há uma distinção entre ambos os níveis (o nível "de cima" do sistema e o nível "de baixo" da ação), algumas teorias intentam, ambiguamente, misturá-los. Algo que leva a modelos inconsistentes. De um lado, há a teoria de Parsons que integra o funcionalismo do sistema à teoria da ação. Parsons vira a estrutura conceitual de Max Weber ao contrário, de modo a subsumir a ação no sistema. De outro, há a teoria de Luhmann que insere os atores no interior dos sistemas autopoiéticos. Os agentes passam a desempenhar relação de ambiente com os sistemas sociais de modo que não são suas ações os elementos que constituem os sistemas, mas sim os eventos comunicativos. Tendo em vista que a teoria da ação e a teoria dos sistemas são duas sociologias com pressupostos analíticos distintos, elas não podem ser associadas em um único modelo.
\end{abstract}

PALAVRAS-CHAVE: Teoria da ação. Teoria dos sistemas. Max Weber. Talcott Parsons. Niklas Luhmann.

\begin{abstract}
In sociological theory there is no consensus on how to integrate the action theory (like Max Weber's classic approach) and the systems theory (such as Talcott Parsons and Niklas Luhmann approaches). By recognizing that there is a distinction between both levels (the "top" level of the system and the "bottom" level of the action), some theories ambiguously attempt to mingle them. This leads to inconsistent models. On the one hand, there is Parsons' theory that integrates the system's functionalism with the theory of action. Parsons turns Max Weber's conceptual framework upside down to subsume the action in the system. Alternatively, there is Luhmann's theory that inserts actors within autopoietic systems. The agents start to play an environmental relation with social systems in a way that their actions are not the elements that constitute the systems, but, rather, communicative events do so. Bearing in mind that action theory and systems theory are two sociologies with different analytical assumptions, they cannot be merged into a single model.
\end{abstract}

KEYWORDS: Theory of action. Systems theory. Max Weber. Talcott Parsons. Niklas Luhmann.

1 Tradução realizada por Bruna dos Santos Bolda (e-mail: bruna.bolda@hotmail.com; orcid: https://orcid.org/0000-0003-4588-1553) e Márcia Inês Schaefer (e-mail: marciainesschaefer@gmail.com; orcid: https://orcid.org/0000-0002-3856-742X), doutorandas em Sociologia e Ciência Política na Universidade Federal de Santa Catarina (UFSC). Texto original publicado em: SCHWINN, Thomas. Lassen sich Handlungsund Systemtheorie verknüpfen? Voraussetzungen systemtheoretischen Denkens bei Talcott Parsons und Niklas Luhmann. In: ___. Max Weber und die Systemtheorie. Studien einer handlungstheoretischen Makrosoziologie. Tübingen: Mohr Siebeck, 2013.

Em Tese, Florianópolis, v. 18, n. 01, p. 103-126, jan./jun., 2021. Universidade Federal de Santa Catarina. ISSN 1806-5023. DOI: https://doi.org/10.5007/1806-5023.2021.e78997 


\section{INTRODUÇÃO}

Max Weber e Talcott Parsons são os autores fundamentais de dois paradigmas centrais da Sociologia: a teoria da ação e a teoria dos sistemas. Embora essa rotulação tenha sido associada ex post a ambos os clássicos, seus trabalhos estabelecem um curso central para o pensamento sociológico. Uma olhada nos numerosos manuais de teoria sociológica - que precisam ser estudados em particular nos cursos básicos - mostra que as linhas teóricas e paradigmáticas que geralmente são seguidas partem desses dois autores. Outro indício para essa tese é fornecido através de um olhar retrospectivo para a história das teorias. Nos seus primeiros anos de trabalho, Talcott Parsons se dedicou intensamente ao estudo e à tradução das obras de Max Weber. Devido ao trabalho de Parsons, não é insignificante a expansão internacional de Max Weber após a Segunda Guerra Mundial. No entanto, a tentativa de Parsons de reunir a obra de Weber e de integrá-la à construção de sua própria teoria falhou. O processo de "desparsonização" das obras de Weber (COHEN et al, 1975) iniciou enquanto Parsons ainda era vivo, acompanhado por inúmeras novas traduções das obras de Weber, o que levou a uma revisão e correção da interpretação de Weber feita por Parsons. As sistematizações dos conceitos fundamentais weberianos em curso atualmente não estão mais baseadas nas diretrizes de Parsons, mas sim desenvolvem os conceitos de forma imanente ${ }^{2}$. Obviamente, Parsons não conseguiu engolir e digerir o "corpo estranho" de Weber. Em uma espécie de reação de rejeição, os paradigmas associados a ele se desenvolvem separados novamente.

Interessam-me essas mudanças nas estratégias conceituais de Weber e de Parsons, pois ambos fundam paradigmas independentes. A peculiaridade do desenvolvimento da Sociologia Compreensiva de Weber fica mais clara se for posicionada e delimitada em relação a uma importante corrente da sociologia, a Teoria dos Sistemas. Uma vez que há diferentes variantes da teoria dos sistemas, irei, em uma segunda etapa, comparar a teoria de Niklas Luhmann com a de Weber. Interessam-me também as demandas atuais, certamente não de Luhmann, de combinação das teorias do sistema e da ação. Nesse sentido, uma indagação que perpassa esse trabalho é: será possível realizar, atualmente,

2 Um exemplo nesse sentido é Wolfgang Schluchter. Em um de seus trabalhos de 1980, a tentativa de desenvolver uma interpretação de Weber a partir das distinções e classificações de Parsons é inconfundível (SCHLUCHTER, 1980). Em uma tentativa semelhante, porém vinte anos mais tarde, esse não é mais o caso (SCHLUCHTER, 2000) ou Parsons está completamente ausente da bibliografia (SCHLUCHTER, 2003). 
o que falhou em Parsons: a convergência e a integração de diferentes teorias sociais em uma teoria abrangente?

\section{PRESSUPOSTOS PARA O PENSAMENTO DA TEORIA DOS SISTEMAS: TALCOTT PARSONS}

Parsons tornou o conceito de sistemas aceitável na sociologia. Por meio de Parsons e de significativo número de alunos seus, o conceito de sistemas passou a fazer parte do pensamento social. A mudança decisiva, que veio atrelada ao conceito de sistemas, é o afastamento da tradição da filosofia do sujeito. Parsons elabora os esboços de sua teoria a partir da filosofia de Alfred N. Whitehead, então seu colega em Harvard (SCHWANENBERG, 1970; WENZEL, 1990; SCHWINN, 1993). Whitehead vê na tradição da filosofia do sujeito um erro fundamental do desenvolvimento do pensamento moderno. Aqui, ele promete remediar substituindo a linha divisória sujeito-objeto da tradição Descartes-Kant por uma concepção radicalmente relacional. Ele acusa o pensamento da filosofia do sujeito da "falácia da concretude deslocada", isto é, de colocar o sujeito como uma entidade inquestionável. Ele se contrapõe a isso com sua filosofia organizacional. Esta divide toda a existência, inclusive os sujeitos, em unidades últimas, chamados de "eventos", e compreende todos os fenômenos como composições ou relações desse elemento fundamental. Esta é também a estratégia analítica de Parsons. O teorema da ordem introduzido por Thomas Hobbes, enquanto fórmula do problema em sociologia, tem apenas o nome em comum com a obra de Parsons. Nas tradições teóricas clássicas da política e da economia, o sujeito era o elemento último da teoria e a ordem o resultado mais ou menos problemático das disputas entre os indivíduos (UDEHN, 2002). O pensamento organístico possibilitou a Parsons pensar a teoria social de uma forma radicalmente nova. Ele removeu o conceito de ação do sujeito e, assim, esquivou-se da problemática tradicional do indivíduo e da sociedade (PARSONS, 1968, p. 72, 355, 367, 737; WENZEL, 1990; SCHWINN, 1993). O próprio ator é um tipo emergente de ordem de ação que mostra um modo específico de relação (PARSONS, 1968, p. 747). Para Parsons, desde o início, o problema da ordem não se limita ao problema da ordem social. Este último é apenas um aspecto do problema em uma ordem geral da ação (sim, da natureza em geral) que pode ser resolvido tanto subjetiva 
quanto objetivamente. Parsons transforma a tradicional dicotomia indivíduo-ordem através de um aumento radical do poder de resolução teórico-social.

Na sociologia de Weber, por outro lado, o sujeito, seja na perspectiva ascendente (a partir "de baixo"), seja na perspectiva ascendente (a partir "de cima"), permanece como o único portador de comportamento significativo, ou seja, uma unidade que não pode ser rastreada até outras instâncias da sociologia ${ }^{3}$. A estratégia de dissociação radical de Parsons desmonta o sujeito da ação e o vincula mais ou menos facilmente à ordem social. Em seus trabalhos iniciais, ele escolheu o "ato-unidade" como o elemento final, o qual é projetado como o menor componente do sistema. O ator ainda faz parte do "ato-unidade", mas não é seu construtor. O quadro de referência da ação é elaborado de tal forma que a unidade de ação a ser definida é determinada como aquela que está inserida em sistemas. Ações são eventos sistematicamente relacionados entre si. Luhmann (1980, p. 07) sugere o seguinte ponto de vista para Parsons: "O agente não é, embora Parsons adote essa terminologia, no sentido estrito, um sujeito [...] de sua ação. Deveríamos antes dizer, para confusão dos ânimos europeus: o sistema da ação é o sujeito do agente". Parsons aperfeiçoou posteriormente a sua técnica de análise com o Esquema AGIL. A realidade organisticamente composta só pode ser abordada com esse sistema de elementos analíticos. Com o Esquema AGIL, cada unidade da qual partimos pode ser decomposta e as relações com a próxima unidade superior podem ser definidas. Esse sistema teórico cumpre, segundo Parsons, o que ele aspirava em seus trabalhos iniciais: a macro perspectiva de um sistema de ação e a micro perspectiva de uma unidade de ação podem ser traduzidas uma pela outra. Com o mesmo esquema, as relações de efeito e as conexões podem ser captadas em todos os níveis de agregação imagináveis.

Ao contrário de Weber, o social não é esclarecido aqui a partir da relação recíproca dos sujeitos atuantes. Para Parsons, esse foi um mal-entendido concreto. O sujeito compreensivo e calculista não tem em sua teoria uma função constitutiva. Portanto, é equivocado separar o trabalho de Parsons em uma teoria da ação e uma teoria do sistema.

\footnotetext{
${ }^{3}$ Albert (2005, p. 209) questiona por que se deve parar diante do sujeito em uma consequente estratégia de análise reducionista e não atribuir sua capacidade de pensar e agir a processos neurológicos e fisiológicos. Isso só não é necessário se assumirmos um "holismo metodológico moderado" que pressupõe emergências em todos os níveis. Não se pode, como no individualismo metodológico, negar a emergência dos fenômenos sociais, mas aceitá-los no sujeito em matéria de seu substrato biológico. No entanto, pode ser questionado que todo o "espectro da realidade" deve seguir um princípio consistente; dizer "uma vez em emergência, sempre em emergência"? Não seria possível que certos fenômenos sejam emergentes e outros não? As pesquisas sobre o cérebro se esforçam para herdar a filosofia do sujeito, todavia resta saber se terão sucesso, por exemplo, para reconstruir a autoconfiança neurofisiologicamente. Afinal de contas, a questão é se pode haver uma ciência que seja completamente livre de metafísica. Sobre o tema "sujeito", compare com o estudo A inevitabilidade da individualidade [Die Unhintergehbarkeit von Individualität] de Frank (1986).
} 
É a mesma apresentação do problema que o ocupa em todos os períodos de criação. Somente podemos falar de um desenraizamento teórico da ação do Esquema AGIL (HABERMAS, 1981, v. II, p. 367) se a definição de ação de Parsons for inadmissivelmente identificada, nos trabalhos iniciais, com a compreensão teórica usual do ator. Isso também é desconhecido por aquelas interpretações que veem Parsons como uma continuidade teórica da ação (TURNER; BEEGHLEY, 1974, p. 48; MÜNCH 1988, p. 190). A teoria da ação de Parsons foi elaborada desde o início de uma forma que está subordinada à teoria dos sistemas.

Isso tem consequências para a teoria da ordem de Parsons. Com a teoria da dualidade de Giddens, pode-se dizer que para ele a ordem é o meio, mas não o resultado da ação. Os níveis de agregação individuais são organizados ciberneticamente de acordo com comandos enérgico-condicionais e culturais. Os respectivos [níveis de agregação individuais $\left.{ }^{4}\right]$ inferiores sempre trazem o momento condicional para dentro dos processos sociais, os quais devem ser moldados pelo controle do próximo e superior [nível de agregação individual ${ }^{5}$. No processo de socialização, o qual é feito ordenadamente através de interações determinantes do desenvolvimento, o sujeito a ser socializado é somente uma condição. Também os níveis de interação não têm, na teoria de Parsons, um direito verdadeiramente próprio, como o problema da dupla contingência pressupunha, mas estão sob influência de normas institucionais, e estas têm, por fim, seu ponto de referência no sistema cultural. Toda a arquitetura conceitual de Parsons deve ser lida de cima para baixo em cada um de seus aspectos. É sempre sobre impor a regulação dos níveis de agregação superiores sobre os níveis de agregação inferiores. Parsons não enfoca o processo oposto - que motivos, orientações e interesses dos atores, interações autônomas decorridas, processos de institucionalização inovadores, por assim dizer - constituem ordens "de baixo para cima" ou modificam diretrizes da ordem, de acordo com a estratégia de Weber nos Grundbegriffen ${ }^{6}$.

Em Parsons, em última análise, trata-se de um modelo idealista de concretização de valor. A acusação de determinismo cultural feita por Habermas (1981, v. II, p. 325; cf. ARCHER, 1988, p. 32; SCHWINN, 1993, p. 245) é, portanto, justificada. A constituição do sujeito, a interação e a institucionalização dependem do padrão cultural. Mais precisamente, deve-se falar de um determinismo cultural sistêmico. As relações

\footnotetext{
${ }^{4}$ Nota das tradutoras: a frase entre colchetes foi inserida pelas tradutoras.

5 Ibidem.

${ }^{6}$ Doravante, Conceitos.
} 
efetivamente ocorridas e as que ainda ocorrerão, fundamentam-se na sistemática do padrão cultural ${ }^{7}$. A ação do sujeito reduz-se a uma realização desse padrão cultural, mas ao mesmo tempo não está envolvido em sua construção. Isso parece contrapor a própria compreensão de Parsons sobre o seu trabalho como uma teoria da "ação voluntarista". Vejamos o que ele entende como "voluntarismo". Sobre a relação entre norma e ação, ele escreve: "A ação deve sempre ser pensada como envolvendo um estado de tensão entre duas ordens diferentes de elementos, o normativo e o condicional. Como processo, ação é, na verdade, o processo de alteração dos elementos condicionais no sentido de conformidade com as normas. [...] Assim, as condições podem ser concebidas em um polo, os fins e as regras normativas no outro, os meios e o esforço como elos de conexão entre eles" (PARSONS, 1968, p. 732). O componente sintetizador do ato-unidade que Parsons designa como esforço é de importância decisiva aqui. Ele liga os elementos de uma unidade de ato. Para ele, esse componente é "a característica central da categoria de ação" (PARSONS, 1968, p. 46). Relacionado a esse conceito, Parsons fala do caráter ativo e criativo da ação (PARSONS, 1968, p. 396, 440). Ele porta o fardo de explicar o conceito de voluntarismo.

A importância sistemática do conceito "esforço" torna-se evidente quando olha-se para a analogia que Parsons faz com o conceito de energia na física (PARSONS, 1968, $p$. 719, 752; PARSONS, 1986, p. 112; PROCTER, 1978, p. 45; SAVAGE, 1981, p. 92). De modo similar aos sistemas mecânicos, que precisam de combustível para manter seus componentes em funcionamento, todo sistema de ação requer energia motivacional para funcionar. O conceito parsoniano "esforço" e, com isso, o de "voluntarismo", não significa o desempenho construtivo de um sujeito, mas tem um significado energético. Isso se torna compreensível quando se relembram as reflexões de Parsons sobre a relação entre norma e ação. O dualismo dos níveis condicional e normativo é constitutivo para toda a sua teoria. Um lado do dualismo, o condicional, não é problemático em seu efeito determinista (PROCTER, 1978, p. 45). Os elementos de hereditariedade e de ambiente prevalecem automaticamente em sua influência causal. Isso não se aplica ao outro lado, o normativo ${ }^{8}$. Aqui, o momento do desempenho é "necessário pelo fato de que normas não se realizam automaticamente" (PARSONS, 1968, p. 719). O status das normas em relação à ação é, portanto, problemático: a fim de obter uma influência causal em relação aos elementos condicionais, as normas exigem que o agente atue como um mediador (PARSONS, 1968,

\footnotetext{
7 Isso remonta a uma figura religiosa do pensamento de Whitehead (Cf. Schwinn, 1993).

${ }^{8}$ Essa ideia fundamenta a distinção de Durkheim entre regras técnicas e morais.
} 
p. 251, 396; SAVAGE, 1981, p. 97, 102). O desempenho do ator no processo de ação reduz-se à ativação energética das normas pré-definidas para dar-lhes uma potência causal em relação à eficácia automática das forças condicionais ${ }^{9}$.

Aqui, a teoria da ação de Parsons apresenta uma lacuna, que possui significado decisivo para toda a arquitetura de sua teoria sociológica (PARSONS, 1974, p. 55; BRADENBURG, 1971, p. 46; PROCTER, 1978, p. 45; LUHMANN, 1980, p. 07; SAVAGE, 1981 , p. 96) ${ }^{10}$. Sua compreensão de voluntarismo oferece uma chave para a interpretação de toda sua obra. As visões contraditórias referentes à sua continuidade ou descontinuidade refletem a falta de clareza sobre o conceito de voluntarismo de Parsons (PROCTER, 1978, p. 45; FITZHENRY, 1986, p. 155).

a) Uma fração de intérpretes vê uma transição da teoria da ação para a teoria dos sistemas. O problema do voluntarismo desaparece completamente na teoria dos sistemas e apenas os processos do sistema são decisivos. Habermas, que segue essa linha interpretativa, vê na fase inicial da teoria da ação de Parsons até mesmo um "conceito monádico da ação", que "começa como uma saída da arbitrariedade privada de atores isolados" (HABERMAS, 1981, v. 2, p. 323) nas decisões orientadas para a ação.

b) Uma outra linha interpretativa não consegue descobrir uma ruptura entre as diferentes fases na obra de Parsons. Parsons também adotou o ponto de vista voluntarista em suas obras posteriores (TURNER; BEEGHLEY, 1974, p. 48; MÜNCH, 1988, p. 190).

\footnotetext{
${ }^{9}$ Por trás dessa concepção, percebe-se a determinação de Whitehead da relação entre o ideal e o real. Os objetos eternos, como possibilidades puras, são inerentemente impotentes e necessitam que o potencial energético da realidade seja concretizado. Por outro lado, a realidade é cega e precisa do ideal como ideia e objetivo orientadores (cf. SCHWINN, 1993, p. 303).

10 Menzies (1976, p. 27) acusa o conceito de voluntarismo de Parsons de ecletismo. Este conceito não é capaz de mediar a situação entre idealismo e positivismo. Warner (1978, p. 1320) fala de um "status redundante do argumento voluntarista": "'voluntarismo' em seu esquema da ação de 1937 é reduzido à questão de transcendência do mero 'natural'. Em outras palavras, o que não pode ser explicado pela hereditariedade ou pelo ambiente é, ipso facto, voluntarista". Giddens (1979, p. 51): "voluntarismo é deste modo, amplamente reduzido a abrir espaço na teoria social para uma explicação da motivação, conectada por meio de normas às características dos sistemas sociais". "Os atores de Parsons são dopados culturais". (Cf. também GIDDENS, 1984, p. 115). Adriaansens (1980, p. 33): "o voluntarismo pode ser formulado primariamente como uma pretensão: uma pretensão de longo alcance" - sem que essa "reivindicação" seja cumprida em Parsons (Idem, 1980, p. 51).
} 
c) Por fim, Ken Menzies (1976, p. 39) vê desde o início do trabalho de Parsons uma teoria da ação e uma teoria do sistema, entre as quais Parsons alterna continuamente.

No entanto, essas interpretações vão na direção errada, uma vez que elas estão baseadas em uma compreensão inadequada do voluntarismo na obra de Parsons. A obra completa de Parsons mostra continuidade em relação a aspectos específicos: "Se a autonomia de escolha-valor é 'fixada' pela determinação normativa de fins e meios, os obstáculos para a realização dos fins irão preocupar o trabalho teórico. Este foco nos obstáculos empíricos para fins sancionados em A Estrutura da Ação Social [The Structure of Social Action] exibe ligações íntimas entre a teoria da ação analítica e a teoria do sistema. Os desenvolvimentos cibernéticos nos escritos posteriores de Parsons sobre evolução [...] não representam uma mudança qualitativa na direção de seu trabalho. $O$ problema de alcançar fins normativamente sancionados é analiticamente similar ao problema cibernético de especificar variáveis de 'estado objetivo' [goal state] de sistemas auto reguladores [...]. As questões hermenêuticas são igualmente irrelevantes para todas as fases do trabalho de Parsons ${ }^{11}$. Decisivo para a continuidade do trabalho de Parsons é o conceito de voluntarismo reduzido ao momento energético, que pode ser facilmente traduzido para a terminologia cibernética. Na dicotomia dos fatores energéticos condicionais e de controle cultural, os sujeitos são prescindíveis como instâncias com autodeterminação. Já no atounidade, objetivos e meios de ação foram determinados normativamente. O sujeito era apenas necessário para sua ativação a fim de entregar a energia motivacional necessária. Essa ideia fundamental também está contida na hierarquia cibernética posterior do Esquema AGIL.

\section{FUNDAMENTOS DA TEORIA DO ATOR NA SOCIOLOGIA DE MAX WEBER}

Se Parsons é o clássico que instituiu a teoria dos sistemas na Sociologia e a tornou aceitável, assim também podemos atribuir os fundamentos clássicos da teoria dos atores a

11 Zaret (1980, p. 1196); cf. também Turner e Beeghley (1974, p. 51): "Por trás do novo vocabulário 'cibernético' está o mesmo impulso revelado em A Estrutura da Ação Social [The Structure of Social Action]”; além disso, Schwinn (1993, p. 347). 
Weber. A diferença entre essas Sociologias pode ser ilustrada pela interpretação e crítica de Parsons aos Conceitos de Weber (PARSONS, 1947, p. 11). As categorias fundamentais de Weber lhe parecem muito estreitas em relação ao problema da ordem. Com o argumento de que a análise dos sistemas sociais deve anteceder a classificação dos motivos determinantes da ação, Parsons vira a estrutura weberiana dos Conceitos de cabeça para baixo. Em sua interpretação, a ação está categorialmente acoplada ao sistema.

Weber, entretanto, não limita sua análise da ação por uma análise preliminar da ordem. Para comportar a possível envergadura de tipos de orientação compreensíveis, Weber mantém deliberadamente os princípios estruturais fora da discussão. A sequência terminológica de Conceitos move-se da ação com sentido subjetivamente visado para a ação social via relação social até a ordem social. Com o sentido subjetivamente visado, a ação não é desvinculada do sujeito e atribuída a quaisquer instâncias coletivas, cuja hipostatização foi o obstáculo de Weber. Para ele, o sujeito é o único portador de comportamento significativo. A estrutura lógica e a sequência de conceitos dos Conceitos refletem essa premissa.

A diferença entre Weber e Parsons é visível também no nível do sentido ou da cultura. Em Parsons, os sujeitos exemplificam e ativam somente o estoque de sentido. Em Weber, eles fundam e constituem o sentido. Isso não deve ser mal compreendido no sentido de sujeitos absolutamente soberanos que refletem sobre os fundamentos do sentido formulados a partir de si mesmos. A saída de Weber para o sentido subjetivamente visado inclui, ao contrário, a perspectiva implícita dos processos de compreensão e de orientação, refrações constitutivas que têm sentido na análise. Ele enfatiza nos Conceitos que uma ação plenamente consciente e clara, na realidade, é apenas um caso-limite. Esses cálculos e perspectivas significativas que Parsons subestimou estão presentes, de acordo com Weber, em todos os níveis de agregação social. "Uma relação social completa e totalmente repousada em um ajuste de sentido mutuamente adequado é, na realidade, apenas um caso-limite" (WEBER, 1980 [1922], p. 14). Também no nível da ordem, Weber acentua o mero caráter de chance que uma ação em conformidade com o sentido [sinngemäßes] e adequada quanto ao sentido [sinnentsprechendes] decorra em extensão digna de nota. Ele explica isso, por exemplo, no conceito de ordem estatal que, na realidade empírica, é uma imensidão difusa, em parte refletida, em parte aceita passivamente ou ações toleradas que correspondem às mais variadas nuances na cabeça dos indivíduos (WEBER, 1982 [1922], p. 200). Para Weber, essa perspectiva não é uma desvalorização ou diluição de um sentido 
objetivo, mas sim sentido relevante para a ação como tal. O sentido objetivo é somente efetivo no "modo de dar-se" [Gegebenheitsweise] do sentido subjetivamente visado"12.

Em uma perspectiva weberiana, uma vez que os eventos sociais passam por fragmentações e refrações significativas, esses eventos seriam equivalentes à hipostatização de um "sistema" que organiza essas relações e processos. Na maioria das vezes, as limitações e a difusão da capacidade do pensamento e da orientação humana são indicadas como argumento para a introdução da teoria dos sistemas. De acordo com Luhmann, por exemplo, a complexidade social excede, de longe, a capacidade de processamento dos sujeitos. O não-intencional [Nicht-Intentionale] se organiza como sistema. Mas como deve haver uma linha sistêmica quando as linhas de compreensão e de ação dos sujeitos não convergem em parte alguma? Por que a ordem, que não existe nos níveis do sujeito e da relação, deve aparecer nos níveis agregados mais altos como "sistema"? De intenções, planos e motivos subjetivos fragmentados e apenas parcialmente sobrepostos, não surgem sistemas não-intencionais claramente delineados. Weber concordaria plenamente com o pressuposto da teoria dos sistemas, de uma capacidade de processamento de complexidade limitada do sujeito. No entanto, disso não se pode concluir a existência e a necessidade do sistema social.

O não-intencional é, em grande medida, uma categoria de imputação. Se as intenções do ator não coincidem claramente, de quais consequências não-previstas [nichtintendierten Folgen] estamos falando? Sem intenções claras não há nenhuma nãointencionalidade claramente marcada. Isso não é, portanto, auto-evidente. De especial importância é quem percebe e tematiza as consequências não intencionais e a quais intenções ou tão somente a quais ignorâncias elas são atribuídas. A perspectiva dos eventos sociais não permite nenhuma versão reificante das entidades sociais. Estes têm somente uma chance ou caráter de probabilidade. O procedimento científico complementar é o método típico-ideal no qual as orientações e as ações dos atores isolados são "pensadas até o fim" de modo "como se" fossem baseadas em um sentido objetivo. A compreensão, por outro lado, não é uma questão fundamental para Parsons. A função de coordenação do sentido e da cultura é não problemática pois os sujeitos não são seus verdadeiros portadores. Ordens se expandem hermeneuticamente de modo contínuo sobre os estoques subjetivos de orientação.

\footnotetext{
12 Cf. os dois primeiros artigos destes volumes: „Max Webers Verstehensbegriff" e "Max Webers Konzeption des Mikro-Makro-Problems".
} 
Embora o sentido seja apenas um determinante comportamental subjetivo, isso não significa que ele é composto somente de uma soma de componentes de sentido subjetivos isolados e que a ordem é reduzida à soma de uma multiplicidade de ações basicamente espalhadas aleatoriamente. Em tal interpretação, a estrutura formal de Conceitos deu motivos para atribuir à Weber um sujeito de ação monológico (HABERMAS, 1981, p. 377) e uma redução subjetivista das estruturas (BADER et al, 1976). Porém, a genealogia conceitual em Conceitos não deve ser mal compreendida, como se fosse baseada em existências individuais monádicas que então iniciam o difícil curso rumo à intersubjetividade ou criam uma constituição livre de pressupostos das ordens e das entidades sociais. Um pressuposto básico do pensamento de Weber é o ser historicamente incorporado da ação. Consequentemente, toda ação não começa em um estado social zero, mas é sempre permeada por disposições estruturais que a precedem. Os Conceitos não estão, por isso, em uma sequência histórica (SCHWINN, 1993, p. 35-93; SCHLUCHTER, 2000, p. 131): quer dizer, na sequência dos conceitos de ação - ação social - relação social - ordem, não há uma constituição histórica livre de pressupostos da ordem na forma de algumas teorias contratualistas $^{13}$. Logicamente, nem as estruturas precedem os atores nem estes precedem aquelas. Ambos devem ser considerados originalmente como iguais. Em Parsons, ao contrário, os sistemas vêm histórica e logicamente antes dos agentes, isso é, em sua interpretação ele só pôde ler os Conceitos em uma direção: nomeadamente, "de cima para baixo". A disposição dos Conceitos antecipa o que posteriormente, na abordagem da escolha racional, é proclamado e praticado como "explicação aprofundada" (COLEMAN, 1987; ESSER, 1993, p. 91): embora as estruturas antecedam historicamente os sujeitos, não há leis macro (MAYNTZ, 2002) com as quais se poderia explicar a reprodução de uma estrutura do momento histórico $\mathrm{t} 1$ até o t2. O caminho indireto deve ser percorrido sempre por uma explicação aprofundada da teoria da ação. Com as três lógicas de Esser ${ }^{14}$ para o esclarecimento do contexto micro-macro, os Conceitos podem ser plena e adequadamente reconstruídos.

Parsons exprime o problema da agregação ou da ordem com o conceito de sistema, Weber, com o conceito de estrutura. Sistema e estrutura trabalham, respectivamente, com

\footnotetext{
13 Para diversas variantes do individualismo metodológico e do individualismo atomístico, consultar Udehn (2002) e Schwinn (2007).

${ }^{14}$ Nota das tradutoras: As três lógicas de Esser são: 1. Lógica da situação; 2. Lógica da ação; e 3. Lógica da agregação e da transformação. Para mais informações, consultar: SELL, Carlos. Em busca do Grande Uno: Hartmut Esser e o modelo Macro-Micro-Macro como síntese final da teoria sociológica. Mediações, Londrina, v. 24 , n. 2, p. 179-203, mai-ago. 2019.
} 
distintas disposições de relacionamento dos requisitos contextuais e com o sujeito agindo no interior delas. O modo como em Parsons o conceito de sujeito é subsumido no conceito de sistema foi descrito na seção anterior. Por outro lado, a relação entre sujeito e estrutura é distinta. A explicação é, nas Ciências Sociais, segundo Weber, sempre uma explicação interpretativa, todo o resto são probabilidades estatísticas incompreensíveis. "Uma interpretação causal correta de uma ação concreta significa: que o decurso externo e o motivo são reconhecidos de maneira exata e, simultaneamente, compreensíveis em seu contexto de sentido" (WEBER, 1980 [1922], p. 05). A reprodução ou transformação de uma ordem de t1 para t2 não pode ser compensada unicamente na conta das condições de restrição e das condições de seleção constantes ou variáveis (= lógica da situação), mas estas devem ser perseguidas sob o crivo dos atores (= lógica da seleção) para compreender e, com isso, poder explicar de maneira causalmente adequada como as condições são traduzidas na ação. Estruturas (ideias, regras, recursos, distribuições de poder, etc.) não devem ser confundidas com ações, elas são, em primeiro lugar, somente diretrizes regulatórias para a ação. Isso pode se fazer claro em uma interpretação teórica da ação do ato-unidade de Parsons: condições e meios situacionais bem como diretrizes normativas devem ser sintetizadas pelo ator. As condições balizadas por fatores não são ainda ordens sociais, no sentido de cursos de ação muito específicos. Fatores estruturais retratam um campo de ação possível e devem ser traduzidos mais ou menos construtivamente na ação. A Sociologia da Religião de Weber, por exemplo, segue esse padrão. Na formação da religião estiveram envolvidos problemas estruturais, condições gerais e noções herdadas. No entanto, as respostas das religiões não são determinadas nem pelos problemas nem pelas noções herdadas. As condições estruturais e as noções herdadas devem ser relacionadas entre si através do desempenho de recepção e de construção das elites religiosas (SCHLUCHTER, 1988, p. 159). Especificamente sobre isso, pode-se esclarecer como o campo de ação possível é usado seletiva e factualmente. É certamente cogitável que os cursos de ação sejam amplamente determinados por claras diretrizes estruturais. Mas esta é uma questão empírica que não deve ser pré-determinada teoricamente. Teoricamente, de qualquer forma, a seletividade e o desempenho de construção dos sujeitos devem ser levados em consideração vis-à-vis com as condições estruturais. 


\section{MAX WEBER E A TEORIA DOS SISTEMAS MAIS RECENTE: NIKLAS LUHMANN}

$\mathrm{Na}$ compreensão de Parsons sobre o sistema, os níveis microscópicos e macroscópicos obedecem a uma conexão contínua que pode ser captada com o esquema AGIL. As relações de efeito e as conexões entre todos os níveis imagináveis de agregação podem ser analisadas com esse esquema. Richard Münch (1988, p. 506) adere a essa técnica de análise e a resume sucintamente:

O sentido dessa aplicação do esquema analítico [AGIL; T.S.] consiste em poder determinar cada vez mais precisamente como um dado aspecto da realidade é determinado, inicialmente, por subsistemas diretamente circundantes em igual nível de abstração, através destes subsistemas que rodeiam o sistema no próximo nível de abstração e assim por diante, até que os respectivos horizontes de toda a área de ação sejam determinados, e como ele próprio ensina, sobre os diversos níveis de abstração até os limites dos efeitos das áreas de ação.

O mundo social obedece, para Parsons, a um plano sólido de construção que reconhece desde uma ação isolada até a sociedade. Não é necessário perguntar pelo sentido subjetivamente visado, como nos Conceitos de Weber; como interligar isto nas relações sociais mais ou menos, parcialmente, em grande parte ou de modo algum coincidentes; e como disso surgem entidades sociais cuja existência baseia-se na chance de que tal ação decorra devidamente em abrangência digna de nota. Na teoria de Parsons, este empreendimento teórico árduo é prescindível porque tudo obedece à lógica inteiramente sistemática do programa AGIL.

Niklas Luhmann realiza algumas conversões na teoria dos sistemas. As relações dos níveis e dos sub-sistemas não obedecem a uma lógica micro-macro contínua, mas devem ser esclarecidas através do modelo sistema-ambiente [System-Umwelt-Modell]. Apropriadamente, ele se opõe ao esquema AGIL por considerá-lo inapto (LUHMANN, 1988). Também o sujeito não é dissolvido organisticamente e integrado perfeitamente à ordem social, como em Parsons, mas está em uma relação de ambiente com os sistemas sociais. Além disso, não são as ações, mas os eventos comunicativos os elementos que constituem os sistemas. Antes da virada autopoiética, as ações ainda eram os elementos de um sistema, embora, ainda assim, não se podia atribuí-las a um sujeito análogo ao atounidade de Parsons (LUHMANN, 1978, p. 213, 216). Com a virada autopoiética, a transição da ação para a comunicação não mudou a "constituição a partir de cima" [Konstitution von 
oben]. "Teoricamente, parece ser controverso se a unidade de um elemento é explicada como emergência 'a partir de baixo' ou pela constituição 'a partir de cima'. Nós optamos pela última concepção indicada. Elementos são elementos somente para os sistemas que eles utilizam como unidade e eles o são apenas através desses sistemas" (LUHMANN, 1984, p. 43). Os Conceitos de Weber tomam o sujeito como ponto de partida. O social não determina o que é uma vasta unidade insolúvel, mas isso é predeterminado ontologicamente. O sujeito, tanto "a partir de baixo" [nach unten] como "a partir de cima" [nach oben], é o limite e a única instância de comportamentos e comunicações significativos. Da constituição dos eventos comunicativos elementares "a partir de cima" não deve ser concluído que Luhmann ignora os micro-eventos. Os sistemas consistem em eventos e eles somente existem enquanto podem fornecer conexão a eventos comunicativos momentâneos que desaparecem imediatamente (LUHMANN, 1984, p. 28, $78,86,388,472,508)$. Além desses fluxos de eventos, os sistemas não têm existência e duração.

Como se passa de um estado do sistema t1 para outro t2? Como uma ordem social emerge desses inúmeros eventos comunicativos? Luhmann está pensando, aqui, em uma "explicação aprofundada" assim como nós identificamos em Weber? Este não é o caso. Luhmann parte da questão de como este fluxo contínuo de eventos é coordenado. Os processos de coordenação são esclarecidos na interação da análise funcional e da teoria dos sistemas (LUHMANN, 1984, p. 83, 404; SCHWINN, 1995). O método funcional é um mecanismo morfogenético criativo que analisa os eventos sobre equivalências funcionais referentes à solução dos problemas do sistema. A seleção de comprovação, o registro dos eventos comunicativos e sua incorporação no repertório estrutural ocorrem com vistas à unidade do sistema. Função significa sempre referência a um problema do sistema social (LUHMANN, 1997, p. 745).

Então, problemas só são problemas se eles não puderem ser isolados, nem trabalhados parte por parte e resolvidos. É justamente isso o que extingue a sua problemática. Há problema, portanto, apenas como problema-sistema [Problem-Systeme] (ou como problemas de sistema [Systemprobleme]). Toda orientação funcional direciona-se, por essa razão, por um contexto indissolúvel (apenas: destrutível). Nós falaremos muito de "diferenciação" [Ausdifferenzierung] de instituições funcionais [Funktionseinrichtungen]; mas isso jamais significa dissolução ou separação do contexto original, mas apenas: estabelecimento das diferenças relacionadas à função dentro dos sistemas, cujos problemas as instituições funcionais se referem. [...] A orientação funcional mantém, consequentemente, o traço holístico junto às teorias do sistema mais antigas (LUHMANN, 1984, p. 84). 
Luhmann parte do princípio de que, portanto, há uma auto-mobilidade funcional e um autocontrole dos acontecimentos do sistema. A autopoiese do sistema social é conduzida pela coordenação funcional da multiplicidade de eventos comunicativos com vista à manutenção do fluxo de reprodução contínua do contexto geral, mas ela não é o resultado agregativo de muitas opções de ação encontradas em contextos situacionais.

A teoria do sistema mais recente tem, com isso, um modelo micro-macro diferente de Weber. Primeiro, ele não é um sujeito que encontra uma opção de ação em um contexto estrutural ou situacional. "A seleção não pode mais ser compreendida, agora, como motivo de um sujeito, não análoga à ação. Ela é um acontecimento sem sujeito" (LUHMANN, 1984, p. 56; cf. também p. 229), conforme demonstrado na obra Sistemas Sociais [Soziale Systeme]. Seleções são realizadas pelos sistemas de interação, sistemas de organização, subsistemas sociais e pelos sistemas sociais. Isso pode ser ilustrado na determinação de relação entre sistemas de interação e sistemas sociais. Todo macrossistema é confrontado com uma multiplicidade de sistemas de interação simples e seleciona, daí, aqueles que podem ser convertidos em um macroestado de capacidade ordenada. O nível do sistema social seleciona o que é capacidade da unidade e capacidade do sistema e bloqueia, com isso, determinados efeitos estruturais potenciais dos microssistemas. O sistema social e o sistema de interação tratam-se, ambos, de sistemas; e sua relação não deve ser pensada segundo o modelo sujeito - relação social - ordem, como em Weber, mas sim segundo o modelo sistema-ambiente. Na teoria de Weber a capacidade de ação é localizada somente no nível do sujeito, isto é, todos os macro-estados devem ser explicados microssociologicamente. Na teoria dos sistemas, ao contrário, a capacidade de sistematização, análoga à capacidade de ação dos sujeitos, é encontrada em todos os níveis do sistema. Uma teoria dos sistemas não pode ter, portanto, uma micro-fundação pura, uma vez que os sistemas de interação e os sistemas sociais não ficam frente a frente com os sujeitos de ação e com a ordem. Na teoria do ator, este último não tem, em princípio, nenhuma capacidade análoga ao sujeito, os macro-sistemas têm, por outro lado, a mesma capacidade dos microssistemas e, por isso, nunca são apenas o explanandum. O macrosistema não é o resultado da agregação dos micro-sistemas. Ambos os níveis do sistema representam, ao contrário, ambientes mutuamente estruturados um para o outro. "As escolhas da estrutura em um tipo de sistema podem, então, incorrer em restrições para as possíveis escolhas da estrutura em outro tipo de sistema. Mas isso não é nenhuma agregação de micro-eventos para um macro-acontecimento" (STICHWEH, 1995, p. 403). 
O sistema de Luhmann não foi, portanto, concebido conforme o modelo de agregação da teoria da ação.

Agora, há também em Weber o pressuposto das consequências não-previstas da ação que parecem resultar em uma vida própria "pelas costas" dos atores, como, por exemplo, o processo de imposição do capitalismo moderno. Não se estaria admitindo aqui, assim como na teoria dos sistemas, um macro-nível quase auto-ativo sob cuja lógica os atores movem-se? Isso chegaria, de acordo com as ideias de Luhmann, a uma constituição "a partir de cima", quer dizer, contrária à argumentação dos Conceitos. Na maioria das vezes, recorre-se ao teorema da emergência nesse contexto. No entanto, para isso, devem ser distinguidas diversas variantes de emergência (STEPHAN, 2000; HEINTZ, 2004; ALBERT, 2005). Na mais recente teoria dos sistemas existe uma noção de emergência forte ou não reducionista: isso é, o nível macro e seus acontecimentos não podem ser explicados por micro-acontecimentos. Essa emergência irredutível pode ser definida da seguinte forma: "uma propriedade sistêmica $E$ de um sistema $S$ é irredutível se o comportamento dos componentes do sistema não resulta de $S$, e, em princípio, não que $S$ tenha propriedade E" (STEPHAN, 2000, p. 39). Do comportamento dos elementos não se pode deduzir quais efeitos isso tem sobre o nível macro. No modelo sistema-ambiente esta ideia está assegurada: do comportamento dos microssistemas no ambiente não resulta nenhuma indicação de como o macro-sistema se comporta. Segundo esse modelo sistemaambiente de Luhmann, os níveis do sistema são analisados desde a interação até a sociedade mundial [Weltgesellschaft]. Mas essa não é a estratégia de Weber. Ele criticou severamente a concepção de emergência irredutível de Röscher e Knies nas Wissenschaftslehre, a qual concede ao nível macro características auto-ativas e autodirigidas: "Os fenômenos culturais individuais, tornados históricos e constatados empiricamente, não são componentes do 'caráter geral', mas o 'caráter geral' é o verdadeiro fundamento dos fenômenos culturais individuais: ele não é algo composto, mas sim unitário, que reflete em todos individualmente" (WEBER, 1982 [1922], p. 142).

Pode-se ler isso também como uma crítica à tese da constituição "a partir de cima" de Luhmann. Toda a estratégia conceitual de Weber, desde os Conceitos, passando pelas sociologias parciais sistemáticas até em direção às análises históricas, é desenvolvida por uma perspectiva de constituição "a partir de baixo". Se se gostaria de utilizar aqui o conceito de emergência, ele é uma noção fraca e redutível de emergência: "As propriedades e disposições comportamentais de um sistema estão atreladas à sua microestrutura, isto é, às propriedades de seus elementos e sua posição. Não pode haver disparidade nas 
propriedades sistêmicas sem que, ao mesmo tempo, haja diferenças nas propriedades dos elementos do sistema ou em seu arranjo" (STEPHAN, 2000, p. 37). O centro do interesse de Weber são as constelações e as variâncias de constelações em seus estudos comparativos (LEPSIUS, 2003, p. 35). A estratégia de comparação só faz sentido se se aceitar uma noção fraca de emergência, uma constituição "a partir de baixo". Diversos decursos evolutivos em distintos meios culturais podem ser atribuídos a constelações variadas de relacionamentos de dominação, classe, economia, religião. Essa estratégia de pesquisa deve partir da redutibilidade do nível macro para que ela faça sentido. Nos estudos de Sociologia da Religião, Weber varia sobretudo o fator religioso e se interessa pelos diversos efeitos e consequências que isso tem. Um conhecimento de outras constelações proporciona, ao mesmo tempo, uma melhor compreensão da própria constelação e seus efeitos. Esse programa de pesquisa não faz sentido sob o pressuposto de um conceito de emergência forte, irredutível: "uma propriedade sistêmica $E$ de um sistema $S$ é irredutível se não resultar do comportamento que os elementos do sistema $S$ demonstram em outras constelações dos arranjos existentes em $S$ e, em princípio, não como eles se comportam em S" (STEPHEN, 2000, p. 40).

\section{A TEORIA DA AÇÃO E A TEORIA DOS SISTEMAS PODEM SER ASSOCIADAS?}

Na obra de Parsons, a teoria dos sistemas ganha uma forma que influencia o pensamento sociológico, comparável à teoria do ator na obra de Weber. A teoria dos sistemas iniciada por Parsons e radicalizada por Luhmann está sujeita a uma transferência de modelo do sujeito para o sistema.

Se se gostaria de aplicar o conceito de sistema desenvolvido em
contextos cibernéticos e biológicos sem perda de nível para o conceito
de sujeito do conhecimento desenvolvido de Descartes até Kant, deve
[...] ser feita uma redisposição. No lugar da relação interno-externo
entre o sujeito cognoscente e o mundo - como a totalidade dos
objetos reconhecíveis - ocorre a relação sistema-ambiente. Para o
desempenho de consciência do sujeito, o conhecimento de mundo e
o autoconhecimento compuseram o problema de referência. Agora,
esse problema é subordinado ao da preservação e expansão da
existência do sistema. A autorreferencialidade do sistema foi
projetada na do sujeito. [...] No lugar da autoconfiança dos sujeitos 
capazes, surgem, consequentemente, sistemas de processamento ou de utilização de sentido (HABERMAS, 1985, p. 426) ${ }^{15}$.

Essa transferência de habilidades análogas ao sujeito para criações sociais tem sérias consequências para explicações sociológicas. A distinção fundamental de sujeito e sistema abre o caminho para ambas as abordagens basais da Sociologia, a teoria da ação e a teoria dos sistemas. Contrariamente à tendência de combinar a teoria do ator e a teoria dos sistemas (HABERMAS, 1981; SCHMANK, 1985; ALEXANDER, 1988; MÜNCH, 1996; ESSER, 2000, p. 31), não vejo isso como um caminho viável. A teoria dos sistemas e a teoria da ação não são estratégias de análise dependentes do objeto, que são selecionadas e combinadas de acordo com o objeto de análise. Elas designam alternativas fundamentais ou metateóricas. Nas tentativas de combinação, geralmente são os teóricos da ação que partem das premissas dessa teoria e, apenas posteriormente, acreditam que devem incorporar o sistema como um fenômeno interdependente da agregação. O que é mal compreendido aqui, é que "sistema" não é uma questão de agregação ou de complexidade de ordem, mas sim uma uma categoria teórica fundamental. Na teoria de Parsons e Luhmann, sistema não é, por assim dizer, além de um divisor de águas social relacionado à complexidade, algo que começa a partir de um dado nível de agregação, mas sim o atounidade e interações simples são concebidos como sistema. Isso foi pensado para ser imanente e consistente à teoria. Se, ao contrário, o sujeito-teórico iniciar com a teoria da ação e for incorporado ao sistema como fenômeno de agregação, confusões serão inevitáveis.

Ambas as teorias fundamentais da Sociologia repousam cada qual em premissas incompatíveis que incorrem em estratégias explicativas incompatíveis. A competência do sistema é, diferentemente da capacidade de ação do sujeito na teoria do ator, atribuída aos eventos sociais em si. Em Parsons há um contexto de sistema contínuo que é identificável com um único esquema ( $A G I L)$, em Luhmann a competência do sistema é encontrada em todos os níveis sociais (interação, organização, sistemas funcionais, sociedade [mundial]) que estão em uma relação sistema-ambiente um com o outro. Na teoria weberiana, ao contrário, apenas uma única instância é capaz de reflexão e capaz de ação, e todos os níveis de ordem são explicados logicamente a partir das ações dos sujeitos. O modelo sistema-ambiente é, aqui, um corpo logicamente estranho porque as ordens não dispõem,

\footnotetext{
15 Cf. também Schwinn (1993, p. 12) e Schmid (2000, p. 134) (onde há mais indicações de literatura sobre a
} apropriação teórica do sistema na Filosofia do Sujeito). 
em princípio, de capacidades de seleção e de auto-estruturação análogas ao sujeito ${ }^{16}$. Embora algo não intencional possa surgir em um contexto de agência, também este não intencional deve ser explicado com o modelo teórico fundamental do sujeito-situação e, ao mudar para o modelo do sistema-ambiente, habilidades análogas ao sujeito não podem ser imputadas repentinamente aos eventos sociais. O não-previsto na sociologia de Weber é algo diferente do sistema da teoria dos sistemas, que já está desvinculado do sujeito por definição e, portanto, em princípio, não pode ser derivado das intenções e relações dos atores, nem no nível micro nem no macro. De acordo com Weber, porém, cada nível social deve ser explicado pelas ações dos atores. Esse é o ensinamento permanente dos Conceitos ${ }^{17}$.

As análises de constelação de Weber não trabalham com a noção de um sistema como a que pode ser encontrada em Parsons e Luhmann. Razões metodológicas também falam contra isso. Um sistema social como uma entidade sempre determinada não pode ser obtido a partir de relações sociais na perspectiva constitucional, nem se pode simplesmente pressupor e derivar daí os componentes e suas relações. É epistemologicamente incompreensível um sistema social no qual as interações sociais experimentam suas determinações. Somente certas partes da totalidade dos eventos sociais são acessíveis para nós. Desde a análise de processos microssociais até contextos macrossociais, sempre encontramos apenas uma amostra de aspectos e fatores para considerar. Quando falamos de "sociedade", sempre falamos apenas de partes especificamente selecionadas de acontecimentos sociais. Alinhada ao sentido da metodologia de Weber, mas sem se referir a ele, Renate Mayntz (2002, p. 39) formula o seguinte:

No entanto, não podemos compreender esta multidimensionalidade da realidade como uma unidade. Nossa percepção é inevitavelmente limitada: sempre selecionamos apenas um ou outro elemento de uma realidade complexa como objeto de explicação e com isso o

${ }^{16}$ Quanto a isso, duas citações de Weber: "O objetivo da consideração: 'compreensão' é, afinal de contas, também o motivo pelo qual a Sociologia Compreensiva... trata [...] o indivíduo isolado e sua ação como a unidade mais baixa, como seu 'átomo' [...]. Porém, pelo mesmo motivo, para esse ponto de vista, o indivíduo é também o limite para cima e o único portador de comportamentos significativos. Nenhuma forma de expressão aparentemente desviante pode ocultar isso" (WEBER, 1982 [1922], p. 439). "Se agora eu sou sociólogo (de acordo com minha certidão de emprego), então, é essencialmente para colocar um fim à operação ainda assombrosa que trabalha com conceitos coletivos" (WEBER apud MOMMSEN, 1974, p. 256, nota 57).

17 Essa compreensão de Weber não me parece adequada e suficientemente levada em consideração em trabalhos mais recentes sobre Weber, que aproximam Weber e Durkheim (BALOG, 2005) e Weber e Luhmann (REHBERG, 2005, p. 453) e enfatizam a importância do teorema da emergência na obra de Weber (ALBERT, 2005). 
analisamos a partir de uma das várias perspectivas possíveis. Cada teoria que trata de um objeto complexo e multifacetado é, correspondentemente, seletiva, considerando tanto as questões que ela coloca ao objeto, quanto aos fatores explicativos que conceitualmente coloca em primeiro plano. Nesse ponto, o ecletismo teórico está - inevitavelmente - nos olhos de quem observa. Mesmo as teorias que visam abranger a totalidade dos fenômenos sociais, como a teoria dos sistemas de Niklas Luhmann, permanecem seletivas enquanto que, por exemplo, elas somente salientam certos princípios fundamentais.

As dificuldades de Luhmann para explicar "todo o processo social" como sistêmico não são fortuitas (SCHWINN, 2001, p. 58).

A atratividade dos modelos da teoria de sistemas está baseada na promessa de poder compensar os efeitos de constelação em uma unidade sistêmica. No entanto, isso permanece uma reivindicação e uma afirmação que eles não podem cumprir por meio de suas análises ${ }^{18}$. Em nenhum lugar os efeitos de uma configuração de ordem convergem em um todo sistêmico, ou podem ser esclarecidos por isso. Para a metodologia de Weber, só pode haver uma análise relativa dos efeitos da constelação referentes ao ponto de vista da seleção, com vistas aos quais os efeitos foram analisados. Esta é a sua abordagem nos estudos comparados de sociologia da religião. "Portanto, esses ensaios não querem ser considerados como análises culturais abrangentes - por mais compactos que sejam. Em vez disso, em cada área cultural eles enfatizam propositalmente o que esteve e o que está contrário ao desenvolvimento da cultura ocidental. Eles são, portanto, plenamente orientados para o que parece ser importante sob este ponto de vista, por ocasião da descrição do desenvolvimento ocidental” (WEBER, 1978 [1920], p. 13, grifos do autor).

\section{REFERÊNCIAS}

ADRIAANSENS, Hans P.M. Talcott Parsons and the Conceptual Dilemma. London, 1980.

ALBERT, Gert. Moderater methodologischer Holismus. Eine weberianische Interpretation des Mikro-Makro-Modells. Kölner Zeitschrift für Soziologie und Sozialpsychologie, v. 57, p. 387-413, 2005.

ALEXANDER, Jeffrey C. Action and its Environments. Toward a New Synthesis. New York, 1988.

${ }^{18}$ Para a crítica dos modelos de sistemas mundiais, consultar Schwinn (2005). 
ARCHER, Margaret S. Culture and Agency. The Place of Culture in Social Theory. Cambridge, 1988.

BADER, Veit-Michael et al. Einführung in die Gesellschaftstheorie. Gesellschaft, Wirtschaft und Staat bei Marx und Weber. Frankfurt/M. u.a, 1976.

BALOG, Andreas. Handlungen und Tatsachen. Weber und Durkheim über die „Objektivität“ des Sozialen. Berliner Journal für Soziologe, v. 14, p. 485-502, 2004.

BRANDENBURG, Alois. Systemzwang und Autonomie. Gesellschaft und Persönlichkeit in der soziologischen Theorie von Talcott Parsons. Düsseldorf, 1971.

COHEN, Jere; HAZELRIGG, Lawrence E.; POPE, Whitney. De-Parsonizing Weber: A Critique of Parsons' Interpretation of Weber's Sociology. American Sociological Review, v. 40, p. $229-241,1975$.

COLEMAN, James S. Microfoundations and Macrosocial Behavior. In: ALEXANDER, Jeffrey et al. (Org.). The Micro-Macro-Link. Berkeley, 1987, p. 153-173.

ESSER, Hartmut. Soziologie. Allgemeine Grundlagen. Frankfurt/M. u.a, 1993.

ESSER, Hartmut. Soziologie. Spezielle Grundlagen. Die Konstruktion der Gesellschaft. $2^{\circ}$ vol. Frankfurt/M. u.a, 2000.

FITZHENRY, Ray. Parsons, Schutz and the Problem of Verstehen. In: HOLTON.; TURNER. (Org.). Talcott Parsons on Economy and Society. London u.a., 1986, S. 143-178.

FRANK, Manfred. Die Unhintergehbarkeit von Individualität. Frankfurt/M, 1986.

GIDDENS, Anthony. Central Problems in Social Theory. Action, Structure and Contradiction in Social Analysis. Berkeley u.a, 1979.

GIDDENS, Anthony. Interpretative Soziologie. Frankfurt/M, 1984.

HABERMAS, Jürgen. Theorie des kommunikativen Handelns. $2^{\mathrm{a}}$ ed. Frankfurt/M, 1981.

HABERMAS, Jürgen. Der philosophische Diskurs der Moderne. Frankfurt/M, 1985.

HEINTZ, Bettina. Emergenz und Reduktion. Neue Perspektiven auf das Mikro-MakroProblem. Kölner Zeitschrift für Soziologie und Sozialpsychologie, v. 56, p. 1-31, 2004.

LEPSIUS, M. Rainer. Eigenart und Potenzial des Weber-Paradigmas. In: ALBERT, Gert et al. (Org.). Das Weber-Paradigma. Tübingen, 2003, p. 32-41.

LUHMANN, Niklas. Handlungstheorie und Systemtheorie. Kölner Zeitschrift für Soziologie und Sozialpsychologie, v. 30, p. 211-227, 1978.

LUHMANN, Niklas. Talcott Parsons - Zur Zukunft eines Theorieprogramms. Zeitschrift für Soziologie, v. 9, n. 1, p. 5-17, 1980. 
LUHMANN, Niklas. Soziale Systeme. Grundriß einer allgemeinen Theorie. Frankfurt/M, 1984.

LUHMANN, Niklas. Warum AGIL?. Kölner Zeitschrift für Soziologie und Sozialpsychologie, v. 40, n. 1, p. 127-139, 1988.

LUHMANN, Niklas. Die Gesellschaft der Gesellschaft. Frankfurt/M, 1997.

MAYNTZ, Renate. Zur Theoriefähigkeit makro-sozialer Analysen. In: (Org). Akteure-Mechanismen-Modelle. Zur Theoriefähigkeit makro-sozialer Analysen. Frankfurt/M. u.a., p. 7-42, 2002.

MENZIES, Ken. Talcott Parsons and the Social Image of Man. London, 1976.

MOMMSEN, Wolfgang. Max Weber. Gesellschaft, Politik und Geschichte. Frankfurt/M, 1974.

MÜNCH, Richard. Theorie des Handelns. Zur Rekonstruktion der Beiträge von Talcott Parsons, Emile Durkheim und Max Weber. Frankfurt/M, 1988.

MÜNCH, Richard. Modernisierung und soziale Integration. Replik auf Thomas Schwinn. Schweizerische Zeitschrift für Soziologie, v. 22, p. 603-629, 1996.

PARSONS, Talcott. Introduction. In: WEBER, Max. The Theory of Social and Economic Organization. Übersetzt von A. M. Henderson und Talcott Parsons. New York, p. 3-86, 1947.

PARSONS, Talcott. The Structure of Social Action. New York, 1968 [1937].

PARSONS, Talcott. Comment on: Current Folklore in the Criticism of Parsonian Action Theory. Sociological Inquiry, v. 44, p. 55-58, 1974.

PARSONS, Talcott. Aktor, Situation und normative Muster. Frankfurt/M, 1986.

PROCTER, lan. Parsons's Early Voluntarism. Sociological Inquiry, v. 48, p. 37-48, 1978.

REHBERG, Karl-Siegbert. Handlungsbezogener Personalismus als Paradigma. Berliner Journal für Soziologie, v. 14, p. 451-461, 2004.

SAVAGE, Stephen P. The Theories of Talcott Parsons. New York, 1981.

SCHIMANK, Uwe. Der mangelnde Akteurbezug systemtheoretischer Erklärungen gesellschaftlicher Differenzierung. Zeitschrift für Soziologie, v. 14, n. 4, p. 421-434, 1985.

SCHLUCHTER, Wolfgang. Gesellschaft und Kultur - Überlegungen zu einer Theorie institutioneller Differenzierung. In: SCHLUCHTER, Wolfgang (Org.). Verhalten, Handeln und System. Talcott Parsons' Beitrag zur Entwicklung der Sozialwissenschaften. Frankfurt/M., p. 106-149, 1980.

SCHLUCHTER, Wolfgang. Religion und Lebensführung. $2^{\mathrm{a}}$ ed. Frankfurt/M, 1988. 
SCHLUCHTER, Wolfgang. Handlungs- und Strukturtheorie nach Max Weber. Berliner Journal für Soziologie, v. 10, p. 125-136, 2000.

SCHLUCHTER, Wolfgang. Handlung, Ordnung und Kultur. Grundzüge eines weberianischen Forschungsprogramms. In: ALBERT, Gert et al. (Org.). Das WeberParadigma. Tübingen, p. 42-74, 2003.

SCHMID, Hans Bernhard. Subjektivität ohne Interität. In: MERZ-BENZ, Peter-Ulrich; WAGNER, Gerhard (Org.). Die Logik der Systeme. Zur Kritik der systemtheoretischen Soziologie Niklas Luhmanns. Konstanz, p. 127-153, 2000.

SCHWANENBERG, Enno. Soziales Handeln. Die Theorie und inr Problem. Stuttgart u.a, 1970.

SCHWINN, Thomas. Jenseits von Subjektivismus und Objektivismus. Max Weber, Alfred Schütz und Talcott Parsons. Berlin, 1993.

SCHWINN, Thomas. Funktion und Gesellschaft. Konstante Probleme trotz Paradigmenwechsel in der Systemtheorie Niklas Luhmanns. Zeitschrift für Soziologie, v. 24, n. 3, p. 196-214, 1995.

SCHWINN, Thomas. Differenzierung ohne Gesellschaft. Umstellung eines soziologischen Konzepts. Weilerswis, 2001.

SCHWINN, Thomas. Weltgesellschaft, multiple Moderne und die Herausforderungen für die soziologische Theorie. Plädoyer für eine mittlere Abstraktionshöhe. In: HEINTZ, Bettina et al. (Org.). Weltgesellschaft. Theoretische Zugänge und empirische Problemlagen (Sonderheft der Zeitschrift für Soziologie). Stuttgart, p. 205-222, 2005.

SCHWINN, Thomas. Individual and Collective Agency. In: OUTHWAITE, William; TURNER, Stephen P. (Org.). Handbook of Social Science Methodology. London, p. 302-315, 2007.

STEPHAN, Achim. Eine kurze Einführung in die Vielfalt und Geschichte emergentistischen Denkens. In: WAGENBAUR, Thomas (Org.). Blinde Emergenz?. Heidelberg, p. 33-47, 2000.

STICHWEH, Rudolf. Systemtheorie und Rational Choice Theorie. Zeitschrift für Soziologie, v. 24, p. 395-406, 1995.

TURNER, Jonathan H.; BEEGHLEY, Leonard. Current Folklore in the Criticism of Parsonian Action Theory. Sociological Inquiry, v. 44, p. 47-55, 1974.

UDEHN, Lars. The Changing Face of Methodological Individualism. Annual Review of Sociology, v. 28, p. 479-507, 2002.

WARNER, R. Stephen. Toward a Redefinition of Action Theory: Paying the Cognitive Element its Due. American Journal of Sociology, v. 83, p. 1317-1349, 1978. 
WEBER, Max. Gesammelte Aufsätze zur Religionssoziologie. vol. 1. $7^{a}$ ed. Tübingen, 1978 [1920].

WEBER, Max. Wirtschaft und Gesellschaft. 5ª ed. Tübingen, 1980 [1922].

WEBER, Max. Gesammelte Aufsätze zur Wissenschaftslehre. $5^{\mathrm{a}}$ ed. Tübingen, 1982 [1922].

WENZEL, Harald. Die Ordnung des Handelns. Talcott Parsons' Theorie des allgemeinen Handlungssystems. Frankfurt/M, 1990.

ZARET, David. From Weber to Parsons and Schütz. The Eclipse of History in Modern Social Theory. American Journal of Sociology, v. 85, p. 1180-1201, 1980.

\section{NOTAS}

TÍTULO DA OBRA

AS TEORIAS DA AÇÃO E DOS SISTEMAS PODEM SER ASSOCIADAS? PRESSUPOSTOS DA TEORIA DOS SISTEMAS DE PARSONS E LUHMANN E DA TEORIA DA AÇÃO DE WEBER

\section{Thomas Schwinn}

Universität Heidelberg, Max-Weber-Institut für Soziologie, Heidelberg, Alemanha

thomas.schwinn@mwi.uni-heidelberg.de

\section{AGRADECIMENTOS}

As tradutoras deste artigo agradecem ao professor Carlos Eduardo Sell pela revisão técnica e à Suellen Próspero pela tradução do resumo e do título para a Língua Inglesa.

LICENÇA DE USO - uso exclusivo da revista

Os autores cedem à Em Tese os direitos exclusivos de primeira publicação, com o trabalho simultaneamente licenciado sob a Licença Creative Commons Attribution 4.0 Internacional (CC BY). Esta licença permite que terceiros remixem, adaptem e criem a partir do trabalho publicado, atribuindo o devido crédito de autoria e publicação inicial neste periódico. Os autores têm autorização para assumir contratos adicionais separadamente, para distribuição não exclusiva da versão do trabalho publicada neste periódico (ex.: publicar em repositório institucional, em site pessoal, publicar uma tradução, ou como capítulo de livro), com reconhecimento de autoria e publicação inicial neste periódico.

PUBLISHER - uso exclusivo da revista

Universidade Federal de Santa Catarina. Programa de Pós-Graduação em Sociologia Política. Publicado no Portal de Periódicos UFSC. As ideias expressadas neste artigo são de responsabilidade de seus autores, não representando, necessariamente, a opinião dos editores ou da universidade.

HISTÓRICO - uso exclusivo da revista

Recebido em: 04 de janeiro de 2021

Aprovado em: 04 de janeiro de 2021 